\title{
Structure and properties of high damping Fe-Ga based alloys
}

\author{
I. S. Golovin ${ }^{1 *}$, V. V. Palacheva ${ }^{1}$, A. A. Emdadi ${ }^{1}$, M. Yu. Zadorozhnyy ${ }^{1}$, A. I. Bazlov ${ }^{1}$ \\ M. V. Gorshenkov ${ }^{1}$, A. V. Pozdniakov ${ }^{1}$, E. S. Savchenko ${ }^{1}$, J. Cifre ${ }^{2}$, R. Barbin ${ }^{3}$, J. Zhu ${ }^{4}$, \\ S. A. Golovin ${ }^{4}$

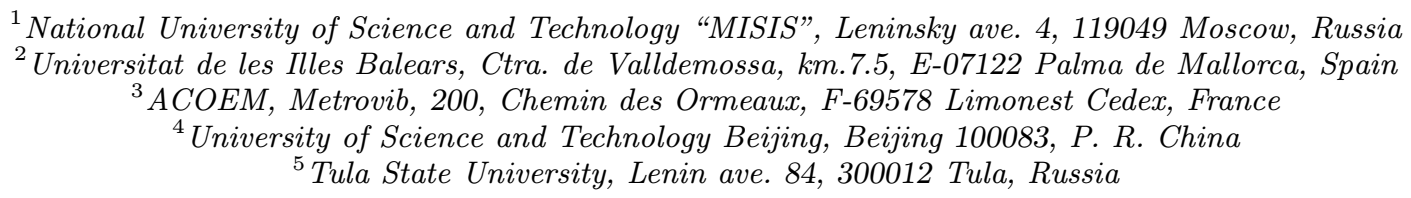

\begin{abstract}
Fe-Ga and Fe-Ga-Al alloys are studied by different mechanical spectroscopy techniques, conventional microscopy, DSC and dilatometry. Main contribution to amplitude dependent damping is assigned to magnetomechanical damping, which is very sensitive to structural state of alloys. Both temperature dependent thermally activated relaxation effects and effects due to phase transitions are discussed in terms of alloy structures and their ordering.
\end{abstract}

K e y w or d s: Fe-Ga, internal friction, damping, ordering

\section{Introduction}

The Fe-Ga alloys have recently become the focus of attention due to their giant magnetostriction in low saturation magnetic fields and good mechanical properties, except maybe low ductility. The magnetostriction $(\lambda)$ of single Fe-Ga crystals approaches $400 \mathrm{ppm}$ along the $<100>$ direction [1]. The magnetostriction of polycrystalline Fe-Ga exhibits a peak near $19 \%$ of $270 \mathrm{ppm}$ [2]. Galfenols have the potential to be widely used in magnetostrictive actuators and sensor devices. They are also good candidates for damping applications [3]. According to the Smith and Birchak's theory [4], the maximal value of damping is proportional to $\lambda$ of ferromagnetic materials: $Q_{\max }^{-1} \sim \lambda$.

It is believed that an increase in the magnetostriction of Fe-Ga alloys is due to the preferential $<001>$ Ga-Ga pairing in the disordered body centered cubic (bcc) structure [5]. Fe-Ga alloys are known by ordering of Ga atoms in bcc iron: the type of order depends on temperature and \% Ga atoms (Fig. 1 [6]). Ordering decreases mobility of magnetic domain walls (MDW) and dislocations, leads to low ductility and decreases damping capacity (DC).

The formation of the equilibrium fcc $\mathrm{L}_{2}$ ordered phase below $630^{\circ} \mathrm{C}$ according to the equilibrium $\mathrm{Fe}-\mathrm{Ga}$ diagram (Fig. 1a) is rather slow, and in most cases the ordering develops in accordance with the metastable diagram (Fig. 1b); at room temperature it is presented by a mixture of $\mathrm{A} 2$ and $\mathrm{D}_{3}$ phases. Quenching suppresses the formation of the $\mathrm{D}_{3}$ structure in favor of a disordered A2 structure and creates freeze-in vacancies. Furnace cooling or annealing of quenched samples may produce two-phase mixture of $\mathrm{A} 2+\mathrm{D}_{3}$ (or $\mathrm{L}_{2}$ ) for alloys with 11-20\% Ga.

Taking into account that the Fe-Ga metastable diagram is similar to the $\mathrm{Fe}-\mathrm{Al}$ phase diagram, it is not surprising that alloys of both systems have a lot in common. Both Al and Ga enhance the magnetostriction of bcc Fe, making a magnetoelastic contribution to damping capacity. Atomic ordering in both systems (equilibrium long-range $\mathrm{D}_{3}$ in $\mathrm{Fe}-\mathrm{Al}$ and equilibrium $\mathrm{L} 1_{2}$ in Fe-Ga) is expected to decrease damping due to pinning of MDW at antiphase boundaries. A short range $\mathrm{D}_{3}$ ordering may take place in both systems under certain conditions: e.g. at slow cooling or annealing.

\section{Experimental procedure}

\subsection{Samples}

In this paper we use at.\%. The Fe-Ga and Fe-Ga- 

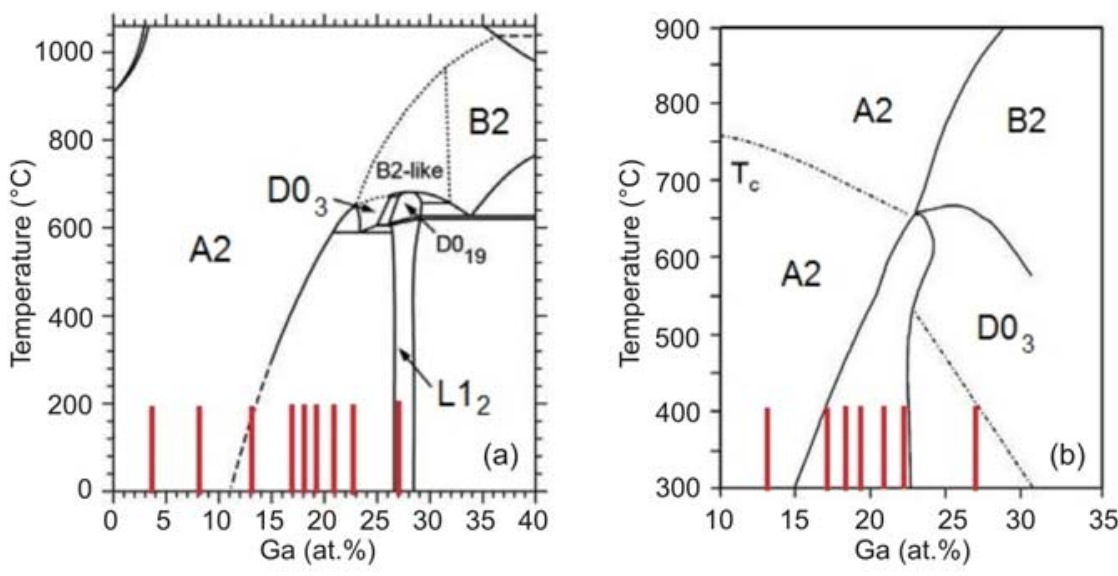

Fig. 1. Stable (a) and metastable (b) Fe-Ga phase diagrams adopted from Ref. [6]. Vertical lines indicate compositions of studied binary alloys.

Table 1. Studied alloys

\begin{tabular}{|c|c|c|}
\hline$n$ & $\begin{array}{l}\text { Nominal } \\
\text { composition }\end{array}$ & $\begin{array}{l}\text { Structure according } \\
\text { to E.D/non-E.D }\end{array}$ \\
\hline 01 & $\mathrm{Fe}-3 \mathrm{Ga}$ & $\mathrm{A} 2$ \\
\hline 02 & $\mathrm{Fe}-8 \mathrm{Ga}$ & $\mathrm{A} 2$ \\
\hline 03 & $\mathrm{Fe}-13 \mathrm{Ga}$ & $\mathrm{A} 2+\mathrm{L} 1_{2} / \mathrm{D}_{3}$ \\
\hline 04 & $\mathrm{Fe}-17 \mathrm{Ga}(\mathrm{NbC})^{*}$ & $\mathrm{~A} 2+\mathrm{L} 1_{2} / \mathrm{D}_{3}$ \\
\hline 05 & $\mathrm{Fe}-18 \mathrm{Ga}(\mathrm{C}, \mathrm{B})$ & $\mathrm{A} 2+\mathrm{L}_{2} / \mathrm{D0}_{3}$ \\
\hline 06 & $\mathrm{Fe}-19 \mathrm{Ga}$ & $\mathrm{A} 2+\mathrm{L}_{2} / \mathrm{D0}_{3}$ \\
\hline 07 & $\mathrm{Fe}-21 \mathrm{Ga}^{*}$ & $\mathrm{~A} 2+\mathrm{L}_{2} / \mathrm{D0}_{3}$ \\
\hline 08 & $\mathrm{Fe}-22 \mathrm{Ga}$ & $\mathrm{A} 2+\mathrm{L} 1_{2} / \mathrm{D}_{3}$ \\
\hline 09 & $\mathrm{Fe}-27 \mathrm{Ga}$ & $\mathrm{L}_{2} / \mathrm{DO}_{3}$ \\
\hline 10 & $\mathrm{Fe}-8 \mathrm{Ga}-4 \mathrm{Al}$ & unknown \\
\hline 11 & Fe-13Ga-5Al & unknown \\
\hline 12 & $\mathrm{Fe}-12 \mathrm{Ga}-6 \mathrm{Al}$ & unknown \\
\hline 13 & Fe-9Ga-8Al & unknown \\
\hline 14 & Fe-6Ga-12Al & unknown \\
\hline 15 & Fe-18Ga-5Al & unknown \\
\hline
\end{tabular}

$\mathrm{ED}$ and n-ED - equilibrium and non-equilibrium phase diagrams

* _ forging plus rolling

-Al alloys were produced by direct solidification. Most of the samples were annealed at $1000^{\circ} \mathrm{C}$ for $40 \mathrm{~min}$, then (i) water quenched $(w q)$, (ii) furnace cooled $(f c)$ or (iii) water quenched and annealed at different temperatures $(w q+a n)$ for $2 \mathrm{~h}$. Information about the studied alloys is collected in Table 1.

\subsection{Methods}

Light microscopy, scanning (SEM) and transmission (TEM) electron and magnetic force (MFM) microscopy, X-ray diffraction (XRD), vibrating sample magnetometry (VSM), heat flow (DSC) and mechanical spectroscopy (MS) were employed in this study. TEM investigations were performed by JEOL
JEM1400 transmission electron microscope operated at $120 \mathrm{kV}$. The thin foils were prepared by electropolishing at a temperature of $-25^{\circ} \mathrm{C}$ and applied voltage of $23 \mathrm{~V}$ in $\mathrm{HClO} 4$-ethanol-2-Butoxyethanol (A2) electrolyte using Struers TenuPol 5 double-jet polisher. Thermal analysis was carried out using Labsys Setaram equipment with heating rates from 20 to $40 \mathrm{~K} \mathrm{~min}^{-1}$. The magnetic hysteresis loop was measured at room temperature (RT) using vibrating sample magnetometer (Foner magnetometer Oxford). The structure of samples was examined by X-ray diffraction (XRD) analysis using a Bruker D8 Advanced diffractometer with $\mathrm{Cu} \mathrm{K} \alpha$ radiation.

MS is the simultaneous testing of anelastic (internal friction, $Q^{-1}$ ) and elastic (Young's modulus, $E)$ properties. We measured frequency-, amplitudeand temperature dependent internal friction (IF) and elastic modulus (FDIF, ADIF, TDIF) using forced bending (dynamical mechanical analyzers Q800 TA Instruments and DMA50 Metravib). IF was measured as $\tan \varphi\left(=Q^{-1}\right)$ at forced vibrations, where $\varphi$ is the phase lag between the applied cyclic stress and the resulting strain: $\sigma=\sigma_{0} \cos (\omega t)$ and $\varepsilon=\varepsilon_{0} \cos (\omega t+\varphi)$; $\omega=2 \pi f$ and $\varphi$ is the phase or loss angle.

\subsection{Results}

FDIF tests were carried out using forced vibrations at DMA (bending, $f$ from 0.01 to $200 \mathrm{~Hz}, \varepsilon_{0}=$ $0.007 \%$ ) and pendulum (torsion, $0.0001-50 \mathrm{~Hz}, \varepsilon_{0}=$ $0.0005 \%$ [7]). Figure. 2a shows DMA tests at RT for several alloys and the choice of frequencies for TDIF tests. Tests performed at $f>30-40 \mathrm{~Hz}$ exhibit an artificial peak-like effect due to an unfortunate ratio of sample and apparatus stiffness: absolute damping values in this range are not reliable. An increase of relaxation time with lowering frequency below $30 \mathrm{~Hz}$ leads to a slight decrease in modulus and increase in damping. The highest reliable damping values in this range 

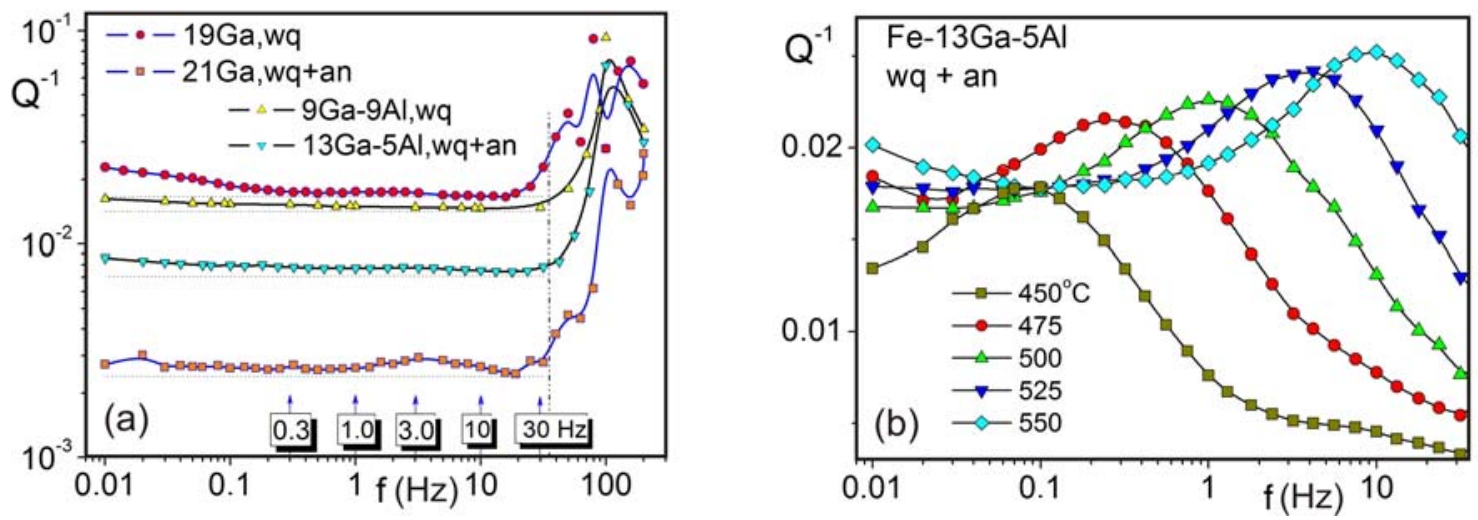

Fig. 2. FDIF tests at (a) RT for several Fe-Ga-(Al) alloys in $w q$ and $w q+$ an states, (b) $450-550^{\circ} \mathrm{C}(\mathrm{P} 3)$ for $\mathrm{Fe}-12 \mathrm{Ga}-5 \mathrm{Al}$ $w q+$ an sample.
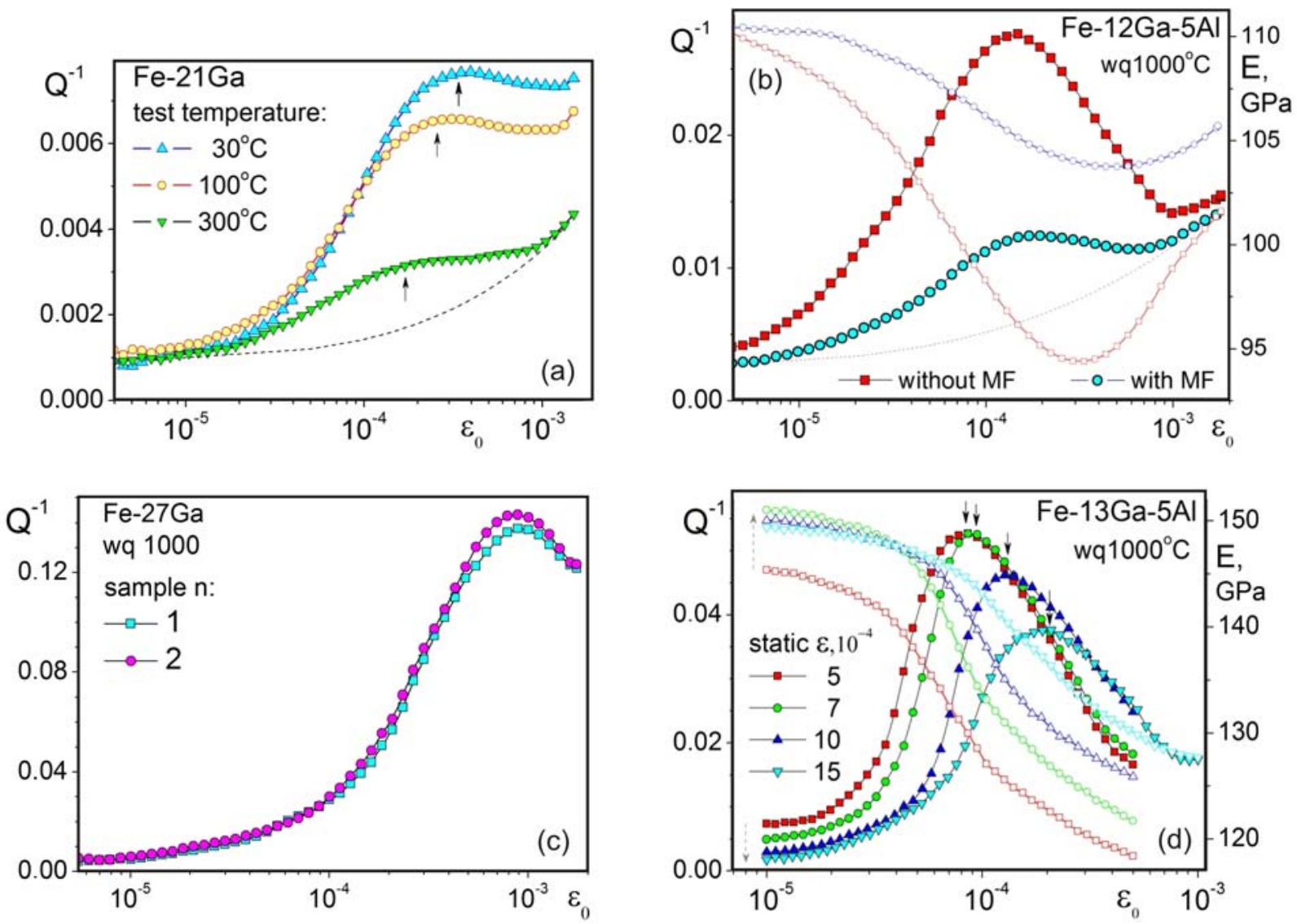

Fig. 3. ADIF tests: (a) at different temperatures, (b) with and without magnetic field, c) after $w q$ and $w q+a n n$, (d) different static stress.

correspond to Fe-19Ga, the lowest - to Fe-21Ga alloys. Tests at $f<0.3 \mathrm{~Hz}$ are time consuming: for TDIF tests with a typical heating rate of $1 \mathrm{~K} \mathrm{~min}^{-1}$ they lead to a low density of experimental points. Thus, five frequencies: $0.3,1,3,10$ and $30 \mathrm{~Hz}$ were chosen for TDIF and $f=3 \mathrm{~Hz}$ for ADIF tests with a fixed temperature. Figure $2 \mathrm{~b}$ shows the FDIF results at $450-550^{\circ} \mathrm{C}$ in the vicinity of the $\mathrm{P} 3$ peak (see below).

ADIF: influence of composition, magnetic field, temperature and scheme of loading. Most of studied Fe-Ga-based alloys exhibit a peak at ADIF at (1$3) \times 10^{-4}$, the height of which decreases with increase in test temperature (Fig. 3a) and in magnetic field (b) proving its magneto-mechanical origin. The influence of heat treatment is complicated: for alloys with $<13 \%$ Ga furnace cooling leads to highest damping, while residual stresses in quenched state decrease damping. For alloys with about $13-20 \%$ Ga quenching 

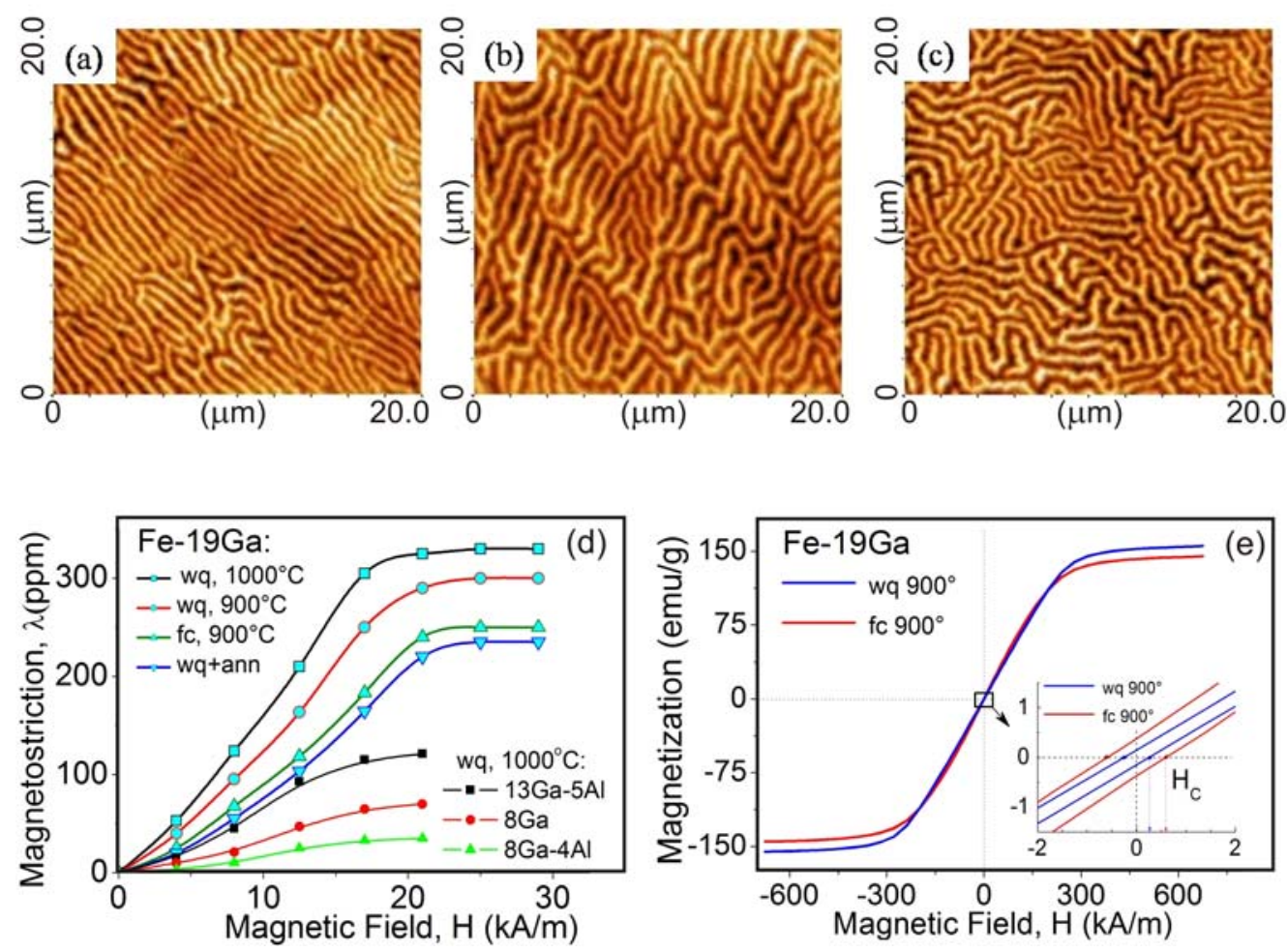

Fig. 4. Magnetic domains in $w q_{900^{\circ}}(\mathrm{a}), f_{900^{\circ}}$ (b) and $w q_{\mathrm{an} 350^{\circ}}$ (c) Fe-19Ga samples; magnetostriction curves (d) for Fe$-19 \mathrm{Ga}\left(w q_{1000^{\circ}}, w q_{900^{\circ}}, f c_{900^{\circ}}, w q_{\text {ann } 350^{\circ}}\right)$ and $w q_{1000^{\circ} \mathrm{C}} \mathrm{Fe}-8 \mathrm{Ga}, \mathrm{Fe}-8 \mathrm{Ga}-4 \mathrm{Al}$ and Fe-13Ga-5Al specimens; Magnetization curves (e) for Fe-19Ga $\left(w q_{900^{\circ}}, f c_{900^{\circ}}\right)$ : inset - data magnification around 0 field.

leads to highest damping; furnace cooling and annealing after quenching decreases damping due to ordering processes in the alloys. In alloys with $21-23 \% \mathrm{Ga}$ damping is low even in water quenched state. Damping in Fe-27Ga becomes again much higher (Fig. 3c).

Absolute damping values depend on test conditions. Three point bending tests exhibit higher damping (d) compared with cantilever tests due to different stress distribution in the sample [8]. Increase in static strain from 5 to $15 \times 10^{-4}$ lowers damping and shifts the peak to higher amplitude. With increase of static stress MDs adjust their shape and volume to applied stress: their mobility under cyclic stress becomes lower and damping decreases. Highest damping at three point bending $(\tan \varphi \approx 0.05)$ is recorded for binary (18-19) \%Ga alloys. Free decay tests give damping nearly twice higher than forced bending vibrations in cantilever mode. Substitution of Ga by $\mathrm{Al}$ atoms decreases damping and magnetostriction (Fig. 4) by $20-25 \%$.

Magnetostriction and the structure of magnetic domains. Magnetic domain patterns of the $w q, f c$, and $w q+$ an Fe-19Ga alloy are shown in Fig. 4 a-c, correspondingly. Stripe-like domains with a high degree of alignment dominate due to an increasing perpendicular anisotropy in the $w q$ sample. Average domain width is $\approx 0.5 \mu \mathrm{m}$ and its length is above $10 \mu \mathrm{m}$. In contrast, irregular maze-like domain patterns with a low degree of alignment typical for ordered atomic structure are found in the $f c$ and $w q+a n$ samples.

Magnetostriction curves for several $w q$ Fe-Ga-based alloys are shown in Fig. 4d, magnetization curves - in Fig. 4e. These figures underline: (i) an increase in $\lambda_{\mathrm{S}}$ with Ga up to $19 \%$; (ii) the role of heat treatment: furnace cooling and annealing after quenching provoke atomic ordering, which opposes magnetic DWs motion, decreases saturation magnetostriction $\lambda_{\mathrm{S}}$ (from 310 to $220 \mathrm{ppm}$ ), magnetization $M_{\mathrm{S}}$ (from 155 to $144 \mathrm{emu} \mathrm{g}^{-1}$ ), and increases coercive force $H_{\mathrm{C}}$ (from 240 to $560 \mathrm{~A} \mathrm{~m}^{-1}$ ) and hardness (HV from 250 to 272-281); (iii) a decrease in $\lambda_{\mathrm{S}}$ with substitution of $\mathrm{Ga}$ or Fe by $\mathrm{Al}$.

Temperature dependent effects. TDIF original results have been presented in our papers $[7,11-17]$. In this paper, we suggest two schemes which describe most of the experimental data (Fig. 5). Both schemes have at least two thermally activated IF peaks $\mathrm{P} 1$ and P3, they also have a range of irreversible structural transition (ST) at $150-300^{\circ} \mathrm{C}$, characterized by an increase in the modulus. The main difference occurs in the range of $300-450{ }^{\circ} \mathrm{C}$. The $\mathrm{P} 2$ peak in scheme (a) is at least partly a thermally activated effect, in contrast the $P_{\operatorname{Tr}}$ peak temperature in scheme (b) does not depend on testing frequency. The relaxation strength of both peaks rapidly decreases with increase in frequency. 

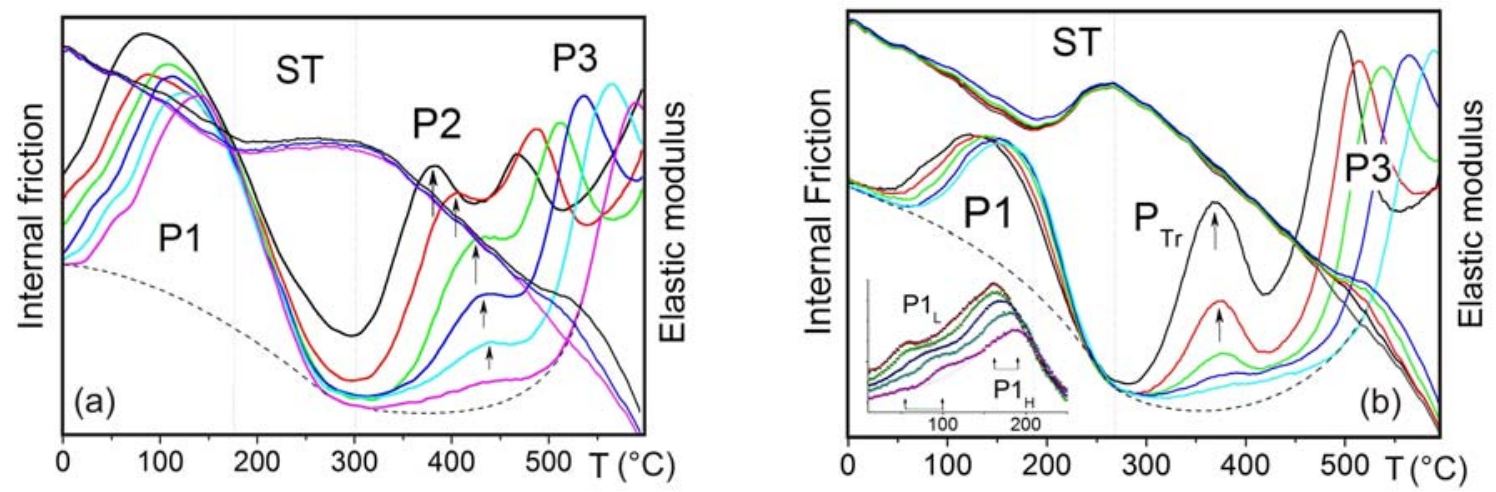

Fig. 5. Typical schemes for TDIF at heating of quenched Fe-Ga alloys.

Table 2. Anelastic effects in selected Fe-Ga-based alloys after water quenching from $1000^{\circ} \mathrm{C}$

\begin{tabular}{|c|c|c|c|c|}
\hline Effect & Alloy & $\begin{array}{c}H(\mathrm{eV}) \\
\text { Heating (Cooling) }\end{array}$ & $\begin{array}{c}\tau_{0}(\mathrm{~s}) \\
\text { Heating (Cooling) }\end{array}$ & Ref. \\
\hline $\mathrm{P} 1_{\mathrm{L}}$ & $\begin{array}{l}\text { Fe-8Ga } \\
\text { Fe-13Ga } \\
\text { Fe-18Ga } \\
\text { Fe-21Ga } \\
\text { Fe- } 8 \mathrm{Al}-3 \mathrm{Ga} \\
\text { Fe-18Ga-5Al }\end{array}$ & $\begin{array}{l}0.95 \pm 0.06 \\
0.88-0.93 \\
0.79 \pm 0.43 \\
0.72 \pm 0.33 \\
0.82 \pm 0.03 \\
1.12 \pm 0.04\end{array}$ & $\begin{array}{l}4 \times 10^{-15} \\
8 \times 10^{-15}-2 \times 10^{-16} \\
2 \times 10^{-13} \\
3 \times 10^{-12} \\
5 \times 10^{-14} \\
4 \times 10^{-16}\end{array}$ & $\begin{array}{l}{[14]} \\
{[16]} \\
{[16]} \\
{[11]} \\
{[17]}\end{array}$ \\
\hline $\mathrm{P} 1_{\mathrm{H}}$ & $\begin{array}{l}\text { Fe- } 8 \mathrm{Ga} \\
\text { Fe-13Ga } \\
\text { Fe-21Ga } \\
\text { Fe-23Ga } \\
\text { Fe-27Ga } \\
\text { Fe- } 8 \mathrm{Al}-3 \mathrm{Ga} \\
\text { Fe-18Ga-5Al }\end{array}$ & $\begin{array}{l}1.29 \pm 0.13 \\
1.04-1.16 \\
1.22 \pm 0.33 \\
1.21 \pm 0.07 \\
1.05 \pm 0.01 \\
1.07 \pm 0.04 \\
1.41 \pm 0.04\end{array}$ & $\begin{array}{l}1 \times 10^{-18} \\
6 \times 10^{-14}-4 \times 10^{-17} \\
2 \times 10^{-18} \\
6 \times 10^{-18} \\
9 \times 10^{-15} \\
4 \times 10^{-16} \\
2 \times 10^{-18}\end{array}$ & $\begin{array}{c}\text { this work } \\
{[7]} \\
{[16]} \\
\text { this work } \\
\text { this work } \\
{[11]} \\
{[17]}\end{array}$ \\
\hline $\mathrm{P} 2$ & $\begin{array}{l}\text { Fe-13Ga } \\
\text { Fe-17Ga } \\
\text { Fe-20Ga }\end{array}$ & $\begin{array}{l}2.43 \pm 0.05 \\
2.12 \\
2.29-2.68(2.44-2.65)\end{array}$ & $\begin{array}{l}1 \times 10^{-17} \\
6 \times 10^{-17} \\
10^{-17}-10^{-18}\left(10^{-18}-10^{-19}\right)\end{array}$ & $\begin{array}{c}{[7,13]} \\
{[14]} \\
{[12]}\end{array}$ \\
\hline P3 & $\begin{array}{l}\text { Fe-17Ga } \\
\text { Fe-18Ga } \\
\text { Fe-21Ga } \\
\text { Fe-23Ga } \\
\text { Fe-8Al-3Ga } \\
\text { Fe-13Al-5Ga }\end{array}$ & $\begin{array}{l}3.19 \pm 0.09 \\
2.70 \\
2.53 \pm 0.05(2.48 \pm 0.07) \\
2.86 \\
2.48 \pm 0.10 \\
2.87 \pm 0.08(2.71 \pm 0.09) \\
2.84 \pm 0.03(2.69 \pm 0.09) \\
2.47 \pm 0.11 \\
2.71 / 2.68 \\
2.8\end{array}$ & $\begin{array}{l}2 \times 10^{-20} \\
2 \times 10^{-16} \\
8 \times 10^{-18}\left(1 \times 10^{-17}\right) \\
3 \times 10^{-20} \\
5 \times 10^{-18} \\
6 \times 10^{-21}\left(6 \times 10^{-20}\right) \\
8 \times 10^{-21}\left(6 \times 10^{-20}\right) \\
7 \times 10^{-18} \\
1 \times 10^{-18} \\
1 \times 10^{-18}\end{array}$ & $\begin{array}{c}\text { this work } \\
{[7,11]} \\
{[13]} \\
{[12]} \\
{[11]} \\
{[15,16]} \\
{[16]} \\
\text { this work } \\
{[11]} \\
{[11]}\end{array}$ \\
\hline
\end{tabular}

The P1 peak (Fig. 5) represents a broad relaxation effect. It can be reliably decomposed into two components in several tests: $\mathrm{P} 1_{\mathrm{L}}$ and $\mathrm{P} 1_{\mathrm{H}}$ (inset to Fig. 5b). According to activation parameters these peaks (Table 2) were interpreted as the Snoek type peaks with two components Fe-C-Fe and $\mathrm{Fe}-\mathrm{C}-(\mathrm{Ga}, \mathrm{Al})$ for alloys containing up to $13 \%$ $\mathrm{Ga}[7,11]$. Addition of strong carbide forming $\mathrm{Nb}$ eliminates these peaks and annealing leads to decrease of IF nearly to the background level shown by the dotted line. In high $\mathrm{Ga}$ containing alloys $(>18 \% \mathrm{Ga})$ one can also distinguish the $\mathrm{P} 1_{\mathrm{L}}$ and $\mathrm{P} 1_{\mathrm{H}}$ peaks, however a structural transition, which starts above $150^{\circ} \mathrm{C}$, suppresses thermally activated relaxation processes and sometimes does not allow reliable calculations of activation parameters. The 
double headed $\mathrm{P} 1$ peak is well recorded in $\mathrm{Fe}-18 \mathrm{Ga}-$ $-5 \mathrm{Al}$ alloy [17].

Structural transition, $S T$, at $150-300^{\circ} \mathrm{C}$ (Fig. 5) is accompanied by relative increase in modulus and contraction at dilatometry tests, an exothermal peak at heat flow, and increase in hardness $[11,15,16]$. From the dependence of 'a peak at heat flow curves $v s$ heating rate' the activation energy of the corresponding process estimated by Kissinger method is in the range from $0.95 \mathrm{eV}$ for binary alloys with $8-13 \%$ Ga to $0.5 \mathrm{eV}$ for alloys with $18-22 \% \mathrm{Ga}$ and ternary $18 \%(\mathrm{Ga}+\mathrm{Al})$ alloys.

After water quenching the structure of samples with $19-27 \% \mathrm{Ga}$ is $\mathrm{A} 2$ (dominating phase) and $\mathrm{D} 0_{3}$. Overlapping of XRD reflections from planes (310) A2 and (620) $\mathrm{D}_{3}$ at around $2 \theta 113-114^{\circ}$ takes place. According to positron annihilation spectroscopy [16] and $\mathrm{XRD}$ [17] studies the main processes in the temperature range of structural transition at $150-300{ }^{\circ} \mathrm{C}$ are decrease in vacancy concentration and $\mathrm{D}_{3}$ ordering. Ordering up to $300^{\circ} \mathrm{C}$ leads to a shift of the main intensity of XRD reflection around $113^{\circ}$ to higher angles, i.e. to $\mathrm{D}_{3}$ structure. Annealing at 400 and $500^{\circ} \mathrm{C}$ leads to nucleation and growth of $\mathrm{L}_{2}$ phase (Fig. 6a). Corresponding microstructure after annealing at $400^{\circ} \mathrm{C}$ during five hours is shown in Fig. 6d.

Above the ST alloys with relatively low Ga \% behave according to scheme (a), i.e. they have a combination of $\mathrm{P} 2$ and $\mathrm{P} 3$ peaks (Fig. 5). The $\mathrm{Fe}-17 \% \mathrm{Ga}-\mathrm{NbC}$ alloys belong to this group, too. For alloys with higher $\mathrm{Ga}$ content and/or additions of $\mathrm{Al}$ the scheme (b) is more typical. Activation parameters of the P2 and P3 peaks calculated using both TDIF and FDIF tests are given in Table 2.

The P2 peak (Fig. 5) temperature increases with saturation due to increase in the test frequency and its height decreases rapidly. Increase in annealing temperature (from 730 to $1100^{\circ} \mathrm{C}$ in $\mathrm{Fe}-17 \mathrm{Ga}$ or from 800 to $900{ }^{\circ} \mathrm{C}$ in $\mathrm{Fe}-13 \mathrm{Ga}$ ) before quenching increases the P2 peak height. The FDIF tests of this peak in Fe-13Ga gave following values for constant temperature: $H=0.85 \mathrm{eV}$ and $\tau_{0}=10^{-6}[7]$, which are very different from TDIF results at instant heating rate $(2.4 \mathrm{eV}$ and $\tau_{0}=10^{-17}[14]$ ), and leave the interpretation of the physical mechanism of this effect open. The frequency independent $\mathrm{P}_{\operatorname{Tr}}$ peak appears in alloys with higher Ga content and it may influence the P2 peak parameters.

The $P_{\operatorname{Tr}}$ peak height (Fig. 5) is irreversibly proportional to measuring frequency: $Q_{\operatorname{Tr}}^{-1}=A \times f^{-1}$, this dependence is known for transient effects in displacive transformations. In [13] we proposed that this peak is due to the $\mathrm{D}_{3} \rightarrow \mathrm{L}_{2}$ transition. Indeed, the formation of short-range $\mathrm{D}_{3}$ ordered domains at the first stage of annealing (according to XRD data - Fig. 6a) or even after quenching (TEM image of $\mathrm{D}_{3}$ domains Fig. $6 \mathrm{~b}$ ) is followed by the $\mathrm{D} 0_{3} \rightarrow \mathrm{L} 1_{2}$ transition at the second stage (Fig. 6a - XRD and Fig. 6d - SEM). Even this transition is diffusion controlled, elements of a displacive shear transformation are involved due to loss of stability or buckling $\{110\}<110>$ of the $\mathrm{D}_{3}$ phase with formation of metastable closed packed structure [18-20]. The Bain strain is required for the diffusionless part of cubic to tetragonal displacive transformation that brings the structure closer to an equilibrium fcc-based $\mathrm{L} 1_{2}$ ordered phase. The features of the $P_{\operatorname{Tr}}$ peak are typical for shear transformations and, thus, it can be associated only with $\mathrm{D}_{3} \rightarrow \mathrm{L}_{2}$ transformation in studied alloys which is well proved by XRD data (Fig. 6a). Huge $P_{\text {Tr }}$ peak is recorded in Fe-27Ga alloy (Fig. 6c) which structure below $620^{\circ} \mathrm{C}$ consists of $100 \% \mathrm{~L}_{2}$ phase according to the equilibrium diagram. The $\mathrm{L}_{2}$ phase appears rapidly in Fe-27Ga alloy above $400{ }^{\circ} \mathrm{C}$ and is identified by XRD, SEM and TEM. Sequence of phase transitions $\mathrm{A} 2 \rightarrow \mathrm{D}_{3}$ (metastable ordered phase) $\rightarrow \mathrm{L}_{2}$ (stable ordered phase) is in agreement with experimental data on temperature dependences of $Q^{-1}, E$, heat flow, dilatometry, positron lifetime and hardness.

The P3 peak is observed in all alloys, except of Fe$-27 \mathrm{Ga}$, at heating, cooling and in subsequent heatingcooling tests, as well as at FDIF tests (Fig. 2b). Activation energy of this peak varies from 2.5 to $3.2 \mathrm{eV}$ and typical values for $\tau_{0}$ range from $10^{-18}$ to $10^{-20} \mathrm{~s}$. These activation parameters correspond to Zener relaxation in Fe-based alloys [21]. The peak height is smaller in the first heating test and it increases at cooling, remaining practically unchanged in the following tests.

At cooling after heating to $600^{\circ} \mathrm{C}$ only the P3 peak is recorded in most alloys and it is slightly higher than at heating (Fig. 7): this is typical for Zener relaxation in alloys with atomic ordering [22]. Decrease in grain size increases the P3 peak relaxation strength and enhances high temperature IF background, while the presence of $\mathrm{NbC}$ particles increases the activation energy of the P3 peak [12] giving some arguments in favour of grain boundary sliding origin of the P3 peak. Heating of $w q$ samples to temperatures below $600^{\circ} \mathrm{C}$ (e.g. $400^{\circ} \mathrm{C}$ ) decreases the $\mathrm{P} 1$ peak, mainly its $\mathrm{P} 1_{\mathrm{H}}$ component, giving additional opportunities to calculate the $\mathrm{P} 1_{\mathrm{L}}$ activation parameters. IF background at cooling increases below the P3 peak with decrease in temperature, which is typical for materials with magnetomechanical damping (Fig. 7). There are some variations: curves of type (1) are recorded in $18 \mathrm{Ga}$, $12 \mathrm{Ga}-5 \mathrm{Al}, 9 \mathrm{Ga}-8 \mathrm{Al}, 5 \mathrm{Ga}-12 \mathrm{Al}$ alloys, (2) in $8 \mathrm{Ga}-4 \mathrm{Al}$, $13 \mathrm{Ga}-5 \mathrm{Al}$, and $(3)$ in $8,13,17,19,21,23 \mathrm{Ga}$ and $8 \mathrm{Al}-$ $-3 \mathrm{Ga}$. Sometimes the difference between types 1 and 3 , 1 and 2 is very small. These variations are due to the competition between two opposite effects: increase of magnetomechanical damping in ferromagnetic phases, mainly in the A2 phase, with lowering temperature, and decrease of damping by nonmagnetic particles of 

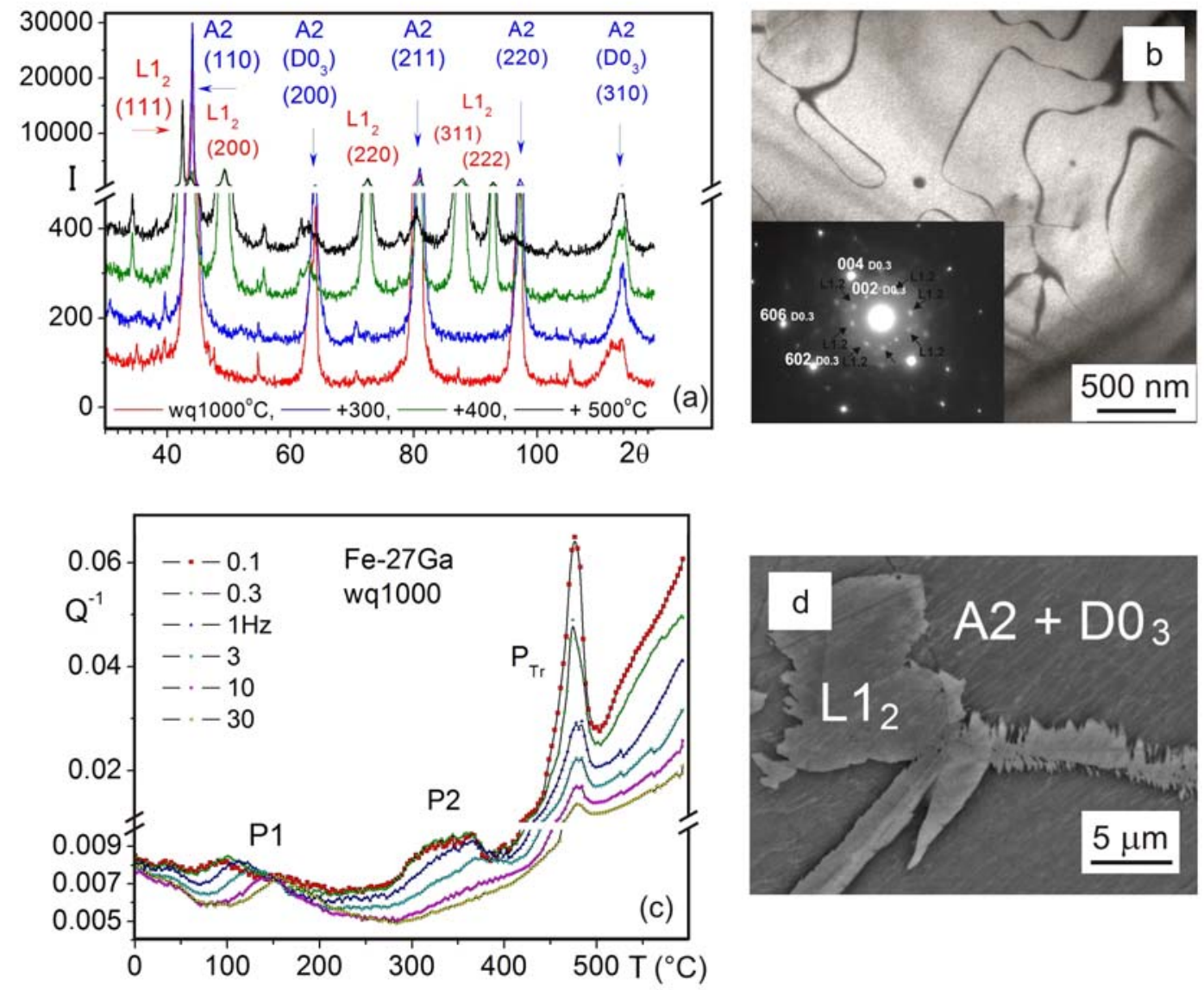

Fig. 6. Fe-27Ga: (a) XRD for water quenched and annealed states, (b) TEM picture after water quenching from $1000^{\circ} \mathrm{C}$ (bright field image taken in $002 \mathrm{D0}_{3}$ reflection and corresponding diffraction pattern (inset) with zone axis [010] $\mathrm{D} 0_{3}$. Black arrows mark weak reflections from L1 $1_{2}$ phase), (c) TDIF for water quenched sample, (d) SEM microstructure after annealing at $400^{\circ} \mathrm{C}, 5 \mathrm{~h}$.

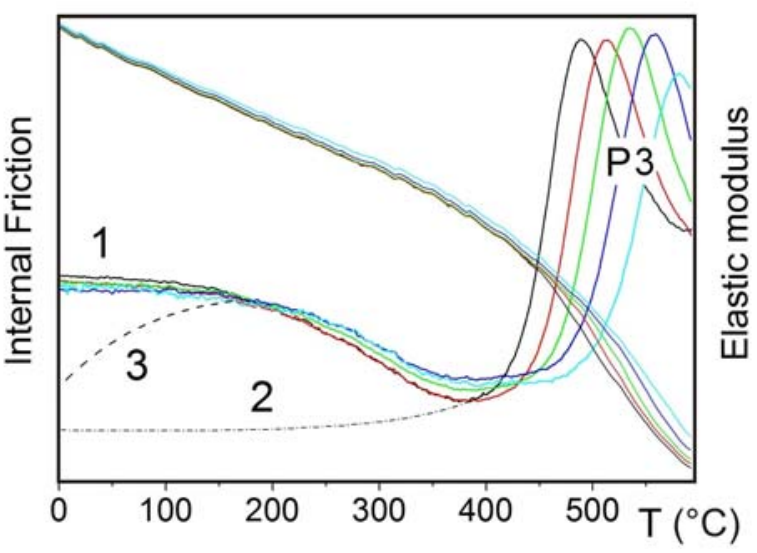

Fig. 7. Scheme for TDIF at cooling.

the $\mathrm{L}_{2}$ phase and the $\mathrm{D}_{3}$ ordering which did not reach their equilibrium during first heating to $600{ }^{\circ} \mathrm{C}$.

\section{Summary}

In this paper we continue our study of hysteretic and relaxation damping mechanisms in steels and iron based alloys published earlier in Kovove Mater. [23, 24]. FDIF, ADIF and TDIF spectrometry of Fe-Ga based alloys with high magnetostriction was carried out. Fe-Ga alloys exhibit rather high damping capacity which increases with increase in Ga content up to $\sim 19$ at. $\%$ ( $\Psi \approx 2 \pi Q^{-1}$ up to $30 \%$ at forced bending vibrations), then it becomes lower at $\mathrm{Ga}>20 \%$, and again reaches maximum at $\mathrm{Ga}$ content 27 at.\%. The main contribution to damping comes from magnetomechanical coupling: the $\mathrm{D0}_{3}$ and $\mathrm{L}_{2}$ ordering suppresses damping. The lower limit at which short range $\mathrm{DO}_{3}$ ordering in $\mathrm{Fe}-\mathrm{Ga}$ alloys may take place is lower than that shown in Fig. 1. This conclusion is in agreement with the results of the transmission synchrotron X-ray study [25], where short range B2 ordering was reported.

In most cases there is a correlation between magnetosctriction values, magnetic structure and damping capacity. The absolute values of damping depend on the test method: forced vibration tests give lower damping compared to free decay tests, cantilever clamping decreases damping compared to three point bending tests, static stress also decreases damping and 
shifts maximum to higher amplitude of vibrations.

Substitution of Ga by Al atoms smoothly decreases damping capacity of Fe-Ga alloys. Aluminium stabilizes the $\mathrm{D}_{3}$ ordered phase. $\mathrm{D}_{3}$ ordering precedes the appearance of the equilibrium $\mathrm{L}_{2}$ phase, the $\mathrm{D0}_{3} \rightarrow$ $\mathrm{L}_{2}$ transition causes the $P_{\text {Tr }}$ peak at TDIF curves at heating. Broad P1 peak represents several relaxation effects caused mainly by point defects, and it is affected by the first step of the ordering reaction: $\mathrm{A} 2 \rightarrow$ $\mathrm{D}_{3}$. The P3 peak is probably due to Zener relaxation. The P2 effect is a combination of thermally activated relaxation effect and effect of the $\mathrm{L}_{2}$ phase nucleation in the alloys.

\section{Acknowledgements}

This paper is set for the Prof. Pavel Lukáč's special edition.

The authors gratefully acknowledge the financial support of the RFBR (Russia) research project 14-03-00165a, the Ministry of Education and Science of the Russian Federation in the frameworks of Increase Competitiveness Program of MISIS and State Task for Universities (1855).

\section{References}

[1] Clark, A. E., Hathaway, K. B., Wun-Fogle, M., Restorff, J. B., Lograsso, T. A., Keppens, V. M., Petculescu, G., Taylor, R. A.: J. Appl. Phys., 93, 2003, p. 8621. doi:10.1063/1.1540130

[2] Srisukhumbowornchai, N., Guruswamy, S.: J. Appl. Phys., 90, 2001, p. 5680. doi:10.1063/1.1412840

[3] Ishimoto, M., Numakura, H., Wuttig, M.: MSE (A), 442, 2006, p. 195. doi:10.1016/j.msea.2006.02.215

[4] Smith, G. W., Birchak, J. R.: J. Appl. Phys., 39, 1968, p. 2311. doi: 10.1063/1.1656551

[5] Ruffoni, M. P., Pascarelli, S., Grossinger, R., Turtelli, R. S., Bormio-Nunes, C., Pettifer, R. F.: Phys. Rev. Lett., 101, 2008, p. 147202. doi:10.1103/PhysRevLett.101.147202

[6] Ikeda, O., Kainuma, R., Ohinuma, I., Fukamichi, K., Ishida, K.: JALCOM, 347, 2002, p. 198. doi:10.1016/S0925-8388(02)00791-0

[7] Golovin, I. S., Rivière, A.: Intermetallics, 19, 2011, p. 453. doi:10.1016/j.intermet.2010.10.017

[8] Xiaofeng, H., Shuwei, L., Xiuyan, L., Lijian, R.: Chinese J. Mat. Research, 27, 2013, p. 225. doi:1005-3093(2013)03-0225-06
[9] Bai, F., Zhang, H., Li, J., Viehland, D.: Applied Physics Letters, 95, 2009, p. 152511. doi: $10.1063 / 1.3238062$

[10] Emdadi, A. A., Cifre, J., Dementeva, O. Yu., Golovin, I. S.: JALCOM, 619, 2015, p. 58. doi: 10.1016/j.jallcom.2014.08.231

[11] Golovin, I. S., Belamri, Z., Hamana, D.: JALCOM, 509, 2011, p. 8165. doi: 10.1016/j.jallcom.2011.04.138

[12] Fang, M., Zhu, J., Golovin, I. S., Li, J., Yuan, Ch., Gao, X.: Intermetallics, 29, 2012, p. 133. doi:10.1016/j.intermet.2012.05.015

[13] Golovin, I. S.: The Physics of Metals and Metallography, 114, 2013, p. 1018. doi:10.1134/S0031918X13090056

[14] Golovin, I. S., Cifre, J.: JALCOM, 584, 2014, p. 322. doi: 10.1016/j.jallcom.2013.09.077

[15] Golovin, I. S., Palacheva, V. V., Zadorozhnyy, V. Yu., Zhu, J., Jiang, H., Cifre, J., Lograsso, T. A.: Acta Materialia, 78, 2014, p. 93. doi:10.1016/j.actamat.2014.05.044

[16] Golovin, I. S., Dubov, L. Yu., Funtikov, Yu. V., Palacheva, V. V., Cifre, J., Hamana, D.: Met. Mat. Trans. A, 46, 2015, p. 1131. doi:10.1007/s11661-014-2721-3

[17] Golovin, I. S., Palacheva, V. V., Bazlov, A. I., Cifre, J., Pons, J.: JALCOM, accepted. doi:10.1016/j.jallcom.2015.04.150

[18] Boisse, J., Zapolsky, H., Khachaturyan, A. G.: Acta Mat., 59, 2011, p. 2656. doi: 10.1016/j.actamat.2011.01.002

[19] Khachaturyan, A. G., Viehland, D. D.: Metal. Mater. Trans. A, 38, 2007, p. 2317. doi:10.1007/s11661-007-9253-z http://www.vupp.cz/czvupp/04bezlepkove/

[20] Khachaturyan, A. G., Viehland, D. D.: Metal. Mater. Trans. A, 38, 2007, p. 2308. doi: $10.1007 / \mathrm{s} 11661-007-9252-0$

[21] Blanter, M. S., Golovin, I. S., Neuhäuser, H., Sinning, H.-R.: Internal Friction in Metallic Materials. A Handbook. Berlin, Springer Verlag 2007.

[22] Golovin, I. S., A. Rivière, A.: Intermetallics, 14, 2006, p. 570. doi:10.1016/j.intermet.2005.09.010

[23] Puškar, A., Golovin S.: Kovove Mater., 16, 1978, p. 426 .

[24] Golovin, S., Puškar, A., Golovin, I.: Kovove Mater., 21, 1983, p. 305.

[25] Du, Y., Huang, M., Chang, S., Schlagel, D. L., Lograsso, T. A., McQueeney, R. J.: Physical Review B, 81, 2010, p. 054432. doi:10.1103/PhysRevB.81.054432 